\title{
Vibration Analysis of a Centrally Clamped Disk
}

\author{
Peter Hudák ${ }^{1 *}$, Ján Ondrejčák ${ }^{2}$, Tomáš Harčarík ${ }^{3}$ \\ 1,2,3 B/S/H/, Drives and Pumps s.r.o., Továrenská 2, 071 90, Michalovce, Slovak Republic
}

\section{BIOGRAPHICAL NOTES}

Ing. Peter Hudák is an development engineer for vibrations and acoustics in B/S/H/. He received his Master level degree at the Department of applied Mechanics and Mechatronics in 2008.

Ing. Ján Ondrejčák is an development engineer for vibrations and acoustics in B/S/H/. He received his Master level degree at the Department of production systems and robotics in 2003.

Ing. Tomáš Harčarik is an development engineer for vibrations and acoustics in $\mathrm{B} / \mathrm{S} / \mathrm{H} /$. He received his Master level degree at the Department of applied Mechanics and Mechatronics in 2009.

\section{KEYWORDS}

Ansys, Polytec PSV400, FEA, EMA, Frequency volume source

\section{ABSTRACT}

This is the abstract section. In the study of modal analysis is it very important to understand the vibrational behavior of parts in order to reduce their contribution to radiated noise. Predicting vibration using today's simulation methods is still restricted by limited knowledge of boundary conditions and material parameters. Using an experimental modal analysis, modal parameters such as mode shapes, natural frequencies, modal damping can be measured. This measured data can be used as input data for numerical simulation. With correlation analysis, the results from finite element analysis (FEA) and experimental modal analysis (EMA) can be compared.

\section{Experimental Modal Analysis}

An experimental analysis was carried out in order to measure disk reference mode shapes, natural frequencies and damping. To be able to compare the results of a measurement with results of simulation, all measured data were exported to LMS Test lab. to post-processing.

\subsection{Setup of the experiment}

Setup of experimental modal analysis is shown in Figure 1. LMS MID frequency volume source (excitation range $200 \mathrm{~Hz}-8000 \mathrm{~Hz}$ ) with real time accurate volume acceleration signal was used for excitation. Distance between measured disk and excitation nozzle was $10 \mathrm{~mm}$ (recommended distance range is from $9 \mathrm{~mm}$ - to $30 \mathrm{~mm}$ ). Non-contact vibration measurements, visualization of mode shapes were performed by Polytec PSV 400 scanning vibrometer. Measured surface was scanned and probed automatically using measurement grid. Non-contact measurement eliminates influence of mass added to the disk. 

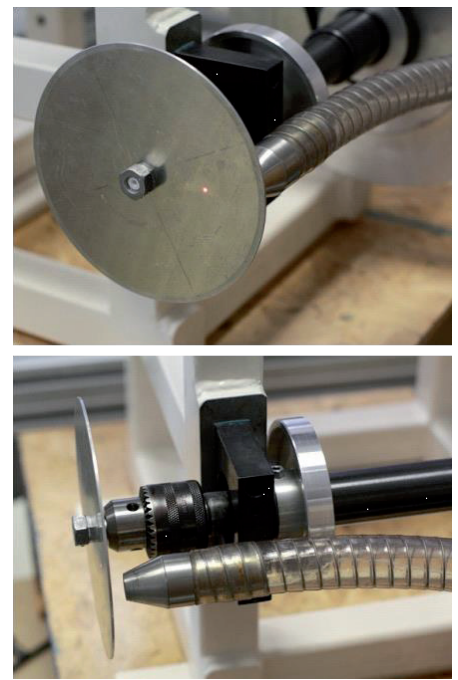

\subsection{Results of EMA}

All experimental modal parameters are obtained from measured operational deflection shapes (ODS). ODS was measured with Polytec PSV 400 scanning vibrometer. Each mode is defined by a natural (modal) frequency, modal damping, and a mode shape. Figure 2 shows the plots of mode shapes and natural frequencies.

\section{Numerical Simulation of Disk in Stationary Condition}

A parallel study using finite element analysis was carried out in order to provide a numerical check of clamped disk. The finite element program Ansys v. 14 was used to compute the natural frequencies and modes. To improve FEM model, results

Fig. 1: Setup of experimental modal analysis

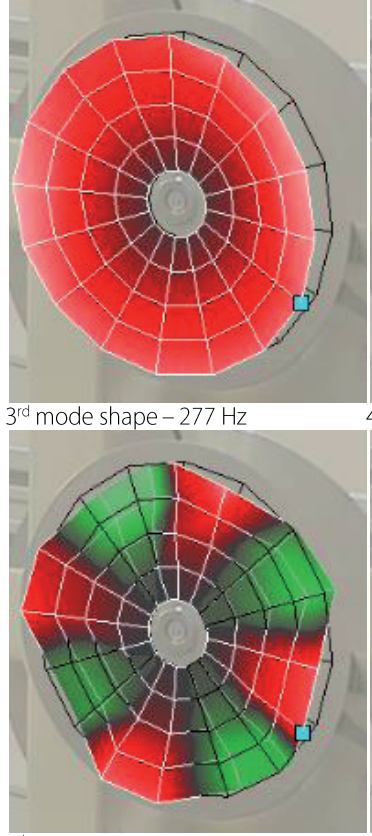

$9^{\text {th }}$ mode shape $-1466 \mathrm{~Hz}$

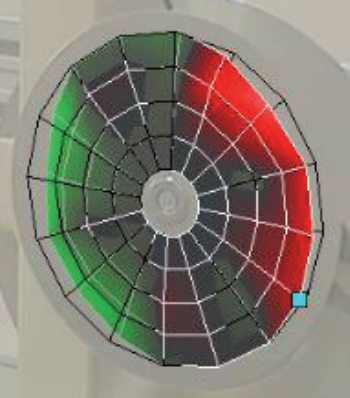

$14^{\text {th }}$ mode shape $-2249 \mathrm{~Hz}$

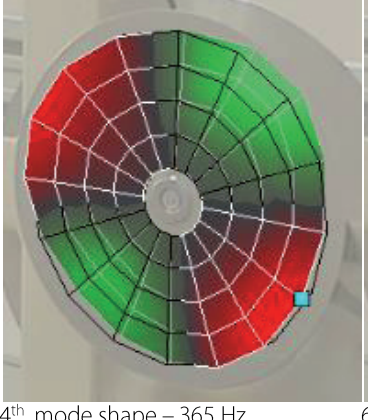

$4^{\text {th }}$ mode shape $-365 \mathrm{~Hz}$

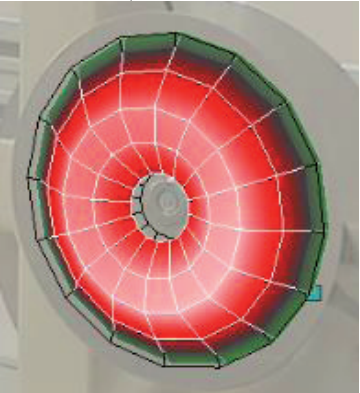

$11^{\text {th }}$ mode shape $-1608 \mathrm{~Hz}$

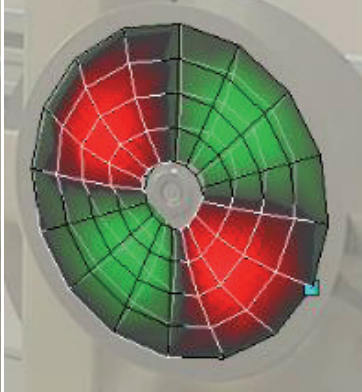

$16^{\text {th }}$ mode shape $-2461 \mathrm{~Hz}$

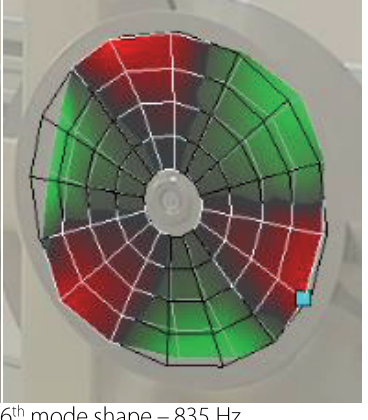

$6^{\text {th }}$ mode shape $-835 \mathrm{~Hz}$

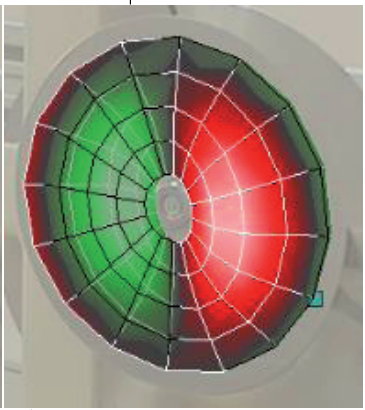

$12^{\text {th }}$ mode shape $-1733 \mathrm{~Hz}$

Fig. 2: Operational deflection shapes and natural frequencies. 
from experimental modal analysis were used. The disk used in the experimental modal analysis was constrained by an internal hub (Figure 3). To eliminate model stiffening in finite element analysis, the hub was added. With fixed inner side of disk, the model was very "stiff". As a result of stiffening, the contact between hub and disk was added. In the finite element model, this contact was considered as bonded with normal stiffness factor 0.2. This set-

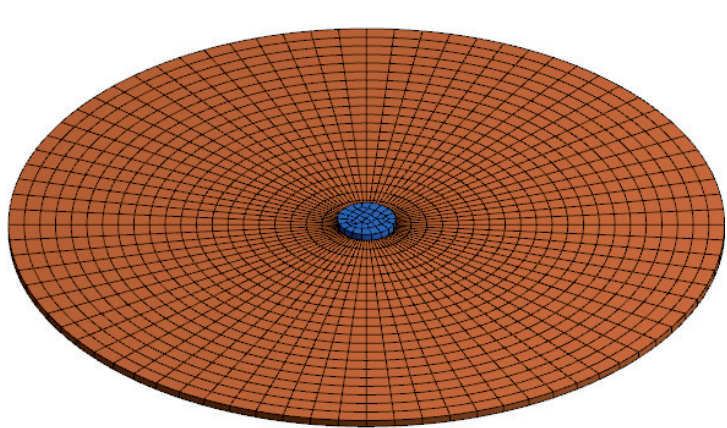

ting eliminates "stiff" effect.

\subsection{Boundary conditions and mesh used in analysis}

Boundary conditions applied on the model:

Fixed support (both surfaces of hub to eliminate very"stiff" model), Material of hub - structural steel, material of disk - aluminum alloy, Bonded contact with normal stiffness factor 0.2 , Frequency range $5-2500 \mathrm{~Hz}$.

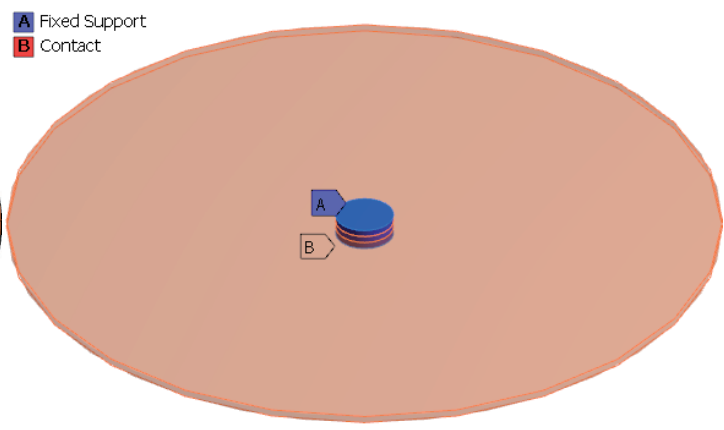

Fig. 3: Mesh and boundary conditions

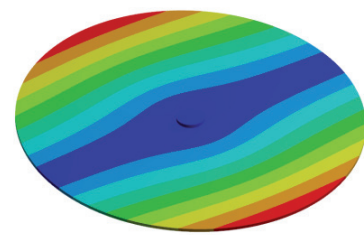

$1^{\text {st }}$ mode shape $\square 206.0 \mathrm{~Hz}$

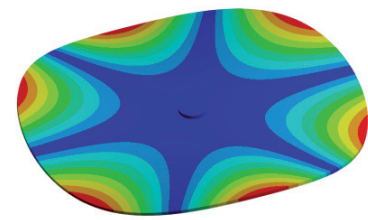

$6^{\text {tn }}$ mode shape $\square 834.8 \mathrm{~Hz}$

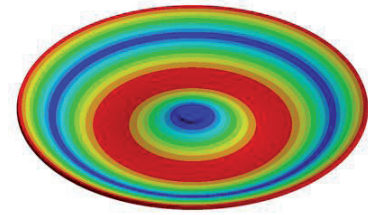

$11^{\text {th }}$ mode shape $\square 1594.5 \mathrm{~Hz}$

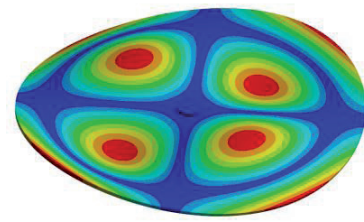

$16^{\text {tn }}$ mode shape $\square 2448.0 \mathrm{~Hz}$

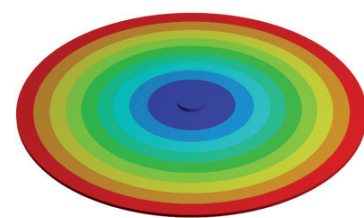

$3^{\text {ra }}$ mode shape $\square 273.3 \mathrm{~Hz}$

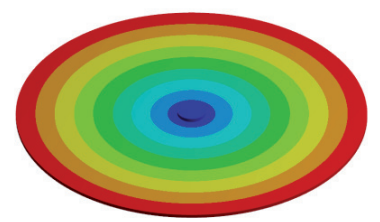

$8^{\text {tn }}$ mode shape $\square 1096.8 \mathrm{~Hz}$

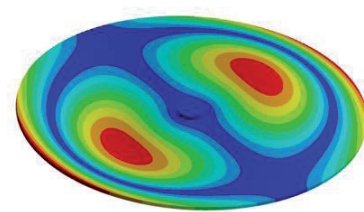

$12^{\text {th }}$ mode shape $\square 1755.8 \mathrm{~Hz}$

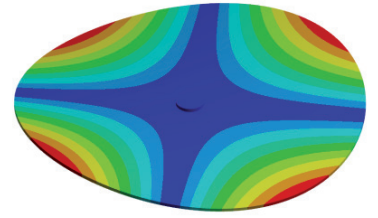

$4^{\text {tn }}$ mode shape $\square 366.5 \mathrm{~Hz}$

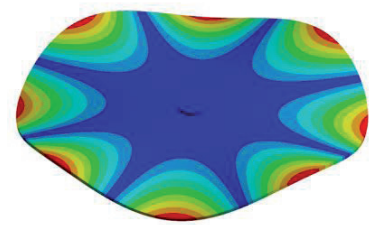

$9^{\text {tn }}$ mode shape $\square 1465.8 \mathrm{~Hz}$

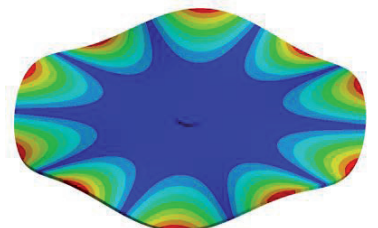

$14^{\text {th }}$ mode shape $\square 2248.5 \mathrm{~Hz}$

Fig. 4: Mode shapes and natural frequencies. 


\subsection{Results of FEA}

Ten calculated mode shapes and frequencies of the centrally clamped disk of the stationary plate rigidly clamped to a pin are shown in Figure 4. The 1 st and 2 nd mode shape is characterized by a one nodal diameter through which the relative phase of displacement changes about $180^{\circ}$. The $3 \mathrm{rd}$ mode shape has nodal points at the center, which is rigidly fixed (umbrella mode). The 4th and 5th mode shapes have four point of maximum curvature with $90^{\circ}$ phase displacement and two nodal diameters. In the case of 6th mode and 7th mode, there are three nodal diameters with six points of maximum. The 8th shape has nodal point at the center which is rigidly fixed and maximum displacement at outer diameter (radial mode). The 9th and 10th shape are characterized by a four nodal diameters with eight points of maximum. The 11 th mode shape has nodal point at center. Maximum curvature region consist of two circular rings along. The 12th and 13th shape is the first buckled shape with one nodal diameter and two point of maximum. In case of 14th mode and 15th mode there are five nodal diameters with ten points of maximum. The 16th and 17th mode is the second buckled shape with two nodal diameters and four points of maximum.

\section{Correlation Analysis}

The modal assurance criteria (MAC) were used in selecting measured points. MAC evaluates the correlation between two different mode shapes. Experimental measured mode shapes and numerically calculated mode shapes. The following equation is used to evaluate MAC values.

$$
\operatorname{MAC}\left\{\psi_{1}, \psi_{2}\right\}=\frac{\left|\left\{\psi_{1}\right\}^{T}\left\{\psi_{2}\right\}\right|^{2}}{\left(\left\{\psi_{1}\right\}^{T}\left\{\psi_{1}\right\}\right)^{T}\left(\left\{\psi_{2}\right\}^{T}\left\{\psi_{2}\right\}\right)^{T}}
$$

In general a higher MAC value indicates better correlation between modes. Two mode shapes with 100\% correlation represents perfect match. The measured mode shapes are compared with the numerically simulated mode shapes. The correlation results in MAC matrix form is presented in figure 5 .

The following interpretation has been suggested for the MAC: a value less than 5\% indicates non-correlated mode shapes and a value higher than 90\% correlated mode shapes. In real life situation a MAC values below $50 \%$ may indicate poor correlation and values above $70 \%$ good correlation. Image 6 shows deformed mapped meshes (right side is measured, left side is numerically simulated) from MAC table.

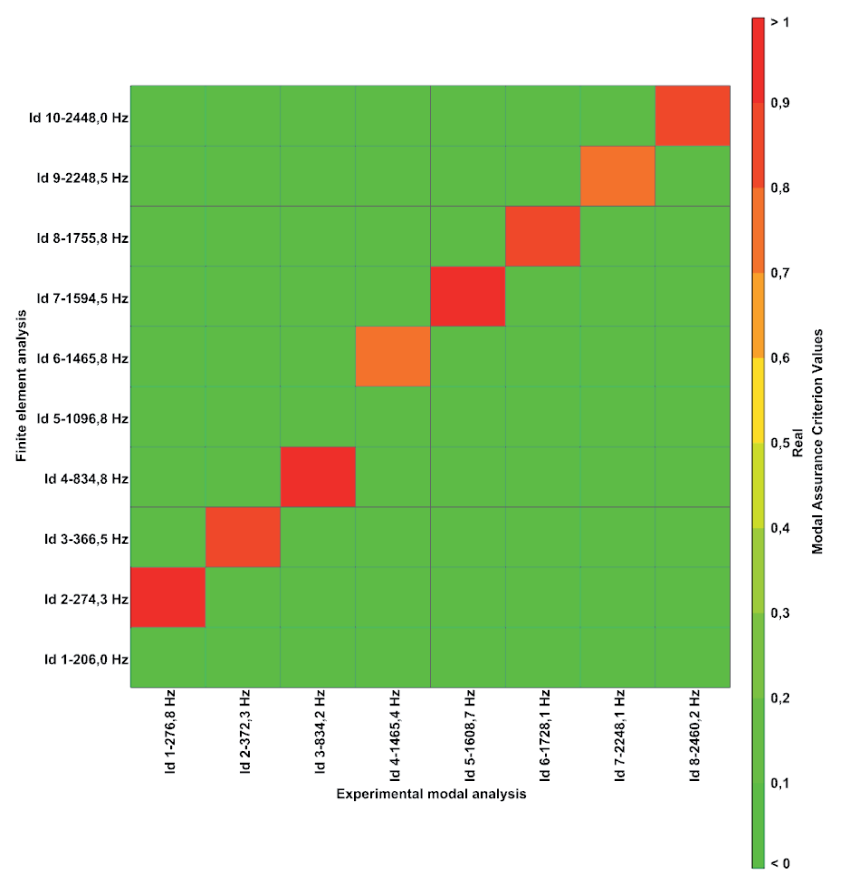

Fig. 5: MAC matrix of measurement and simulation. 


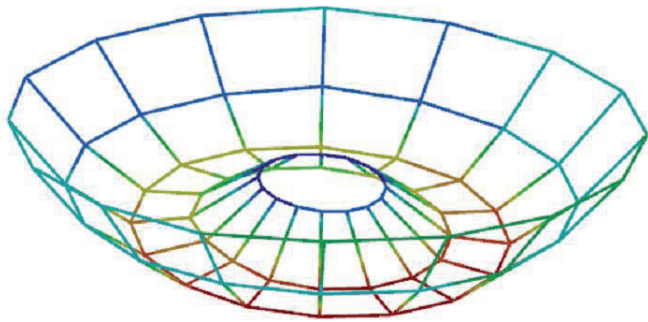

Fig. 6: MAC Mode pair table results of $1594 \mathrm{~Hz}$ and $1608 \mathrm{~Hz}$

\section{Conclusion}

Combination of non-contact scanning vibrometry and the numerical simulation is powerful method to predict vibrational behavior of structures. The measurement was made with zero influence of mass under operating conditions. Two mode shapes and frequencies which wouldn't have been visible with measurement were visible in numerical simulation. Contact stiffness between hub and disk changed only lower shapes of the disk. Modal shapes, where nodal diameter crosses the hub, were influenced by frequency. Summarized results of analysis are shown in Table 1. Errors of natural frequencies numerically computed and measured is under $2 \%$ and can be caused by non-precise disk production. The lowest value of correlation is $74 \%$. This procedure can be used with complicated parts of machines to eliminate errors in numerical simulations.

Table 1: Values of FEA, EMA, Correlation and Damping

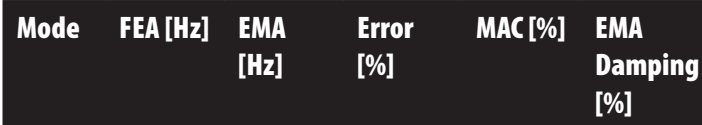

\begin{tabular}{|l|l|l|l|l|l|}
\hline 1 & 206 & - & - & - & - \\
\hline 2 & 273,3 & 276,8 & $1,3 \%$ & $99 \%$ & $0,2642 \%$ \\
\hline 3 & 366,5 & 372,3 & $1,6 \%$ & $80 \%$ & $0,0754 \%$ \\
\hline 4 & 834,8 & 834,2 & $-0,1 \%$ & $97 \%$ & $0,2370 \%$ \\
\hline 5 & 1096,8 & - & - & - & - \\
\hline 6 & 1465,8 & 1465,4 & $0,0 \%$ & $74 \%$ & $0,0217 \%$ \\
\hline 7 & 1594,5 & 1608,7 & $0,9 \%$ & $92 \%$ & $0,5741 \%$ \\
\hline 8 & 1755,8 & 1728,1 & $-1,6 \%$ & $88 \%$ & $0,5390 \%$ \\
\hline 9 & 2248,5 & 2248,1 & $0,0 \%$ & $75 \%$ & $0,0153 \%$ \\
\hline 10 & 2448 & 2460,2 & $0,5 \%$ & $80 \%$ & $0,0412 \%$ \\
\hline
\end{tabular}

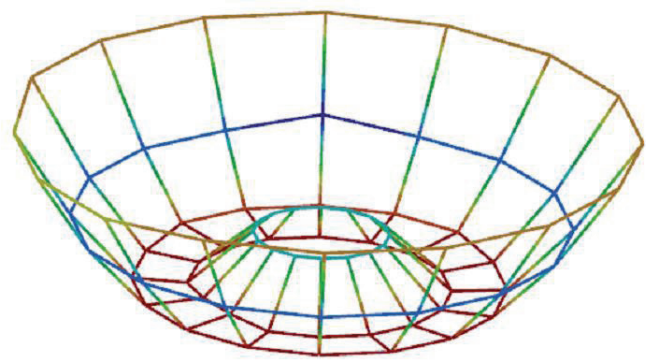

\section{References}

[1] Ranjan V., Ghosh M.K., 2009. Transverse vibration of spinning disk with attached distributed patch and diskrete point masses using finite element analysis. In.: International journal of engineering, Science and Technology, Vol.1, Issue.1 pp. 74-89, ISSN: 2141-2839

[2] MacBain J.C., Horner, J.E., Stange W.A., Ogg J.S.,1979. Vibration analysis of a spinning disk using image-derotated holographic interferometry. In.: Experimental mechanics, Vol.19, Issue 1. Pp. 17-22, ISSN: 1741-2765

[3] Trebuňa, F., Frankovský, P., Huňady, R.: Optical methods and their application in experimental analysis of mechanical and mechatronic systems. In: Hutnické listy. Vol. 64, no. 7 (2011), p. 173-178. ISSN 0018-8069

[4] Trebuňa, F., Huňady, R., Frankovský, P.: Metóda digitálnej obrazovej korelácie. In: Strojárstvo extra. Č. 9 (2011), s. 4-6. - ISSN 1335-2938

[5] Trebuňa, F., Frankovský, P., Huňady, R.: The Use of Optical Methods in Experimental Analysis of Mechanical and Mechatronic Systems. In: Machine Modeling and Simulations 2011. Púchov: Faculty of Industrial Technologies, University of Alexander Dubček in Trenčín, 2011 S. 249-256. - ISBN 97880-8075-494-5 